\title{
Manifestações Otorrinolaringológicas nas Doenças Reumáticas Auto-Imunes
}

\section{Otorhinolaryngologic Manifestations of Autoimmune Rheumatic Diseases}

\author{
Daniela Bergamim Pereira ${ }^{(1)}$, Juliana Lasmar Ayres do Amaral ${ }^{(1)}$, José Carlos Mansur Szajubok ${ }^{(2)}$, Sônia \\ Maria Anti Loduca Lima ${ }^{(3)}$, Wiliam Habib Chahade( ${ }^{(4)}$
}

\section{RESUMO}

As manifestações otorrinolaringológicas nas doenças reumáticas representam um desafio diagnóstico para o reumatologista, o otorrinolaringologista e o médico generalista. Comumente, sintomas otorrinolaringológicos representam um sinal inicial de uma doença assintomática ou uma desordem auto-imune não diagnosticada, que freqüentemente exige um imediato e agressivo tratamento imunossupressor. Distúrbios auditivos podem ser vistos em pacientes com lúpus eritematoso sistêmico (LES), granulomatose de Wegener (GW), policondrite recidivante (PR), poliarterite nodosa, síndrome de Cogan, síndrome de Sjögren e menos freqüentemente na síndrome de Churg-Strauss e doença de Behçet. O nariz e seios paranasais são variavelmente afetados durante o curso da GW, síndrome de Churg-Strauss, PR e sarcoidose. Ulcerações mucosas recorrentes são comuns no LES e doença de Behçet. Xerostomia é uma manifestação comum da síndrome de Sjögren primária e secundária; aumento da glândula salivar pode ser visto nesses pacientes, assim como nos pacientes com sarcoidose. A articulação cricoaritenóide pode ser envolvida durante o curso da artrite reumatóide, espondilite anquilosante e gota; alterações osteoartríticas também têm sido descritas. Disfunção do nervo trigeminal pode ocorrer em pacientes com síndrome de Sjögren, esclerose sistêmica, LES e doença mista do tecido conjuntivo. Paralisia facial periférica tem sido descrita como complicação do curso da síndrome de Sjögren e sarcoidose.

Palavras-chave: distúrbios auto-imunes, perda auditiva, sinusite, rouquidão, úlceras orais.

\begin{abstract}
Otorhinolaryngologics manifestations of rheumatologic disorders represent a diagnostic challenge for the rheumatologist, the otorhinolaryngologist, and the general practicioner. Not uncommonly otorhinolaryngologics symptoms represent the initial sign of an otherwise asymptomatic or even undiagnosed autoimmune disorder which often calls for prompt and aggressive immunosuppressive treatment. Hearing disturbances may be seen in patients with systemic lupus erythematosus, Wegener's granulomatosis, relapsing polychondritis, polyarteritis nodosa, Cogan's syndrome, Sjögren's syndrome, and less frequently in Churg-Strauss syndrome and Behçet's disease. Nose and paranasal sinuses are variably affected during the course of Wegener's granulomatosis, Churg-Strauss syndrome, relapsing polychondritis and sarcoidosis. Recurrent mucosal ulcerations are common in systemic lupus erythematosus and Behçet's disease. Xerostomia is a common feature of primary and secondary Sjögren's syndrome; salivary gland enlargement may be also seen in these patients, as well as in patients with sarcoidosis. The cricoarytenoid joint can be involved during the course of rheumatoid arthritis, ankylosing spondylitis and gout; osteoarthritic changes have also been described. Trigeminal nerve dysfunction may occur in patients with Sjögren's syndrome, systemic sclerosis, systemic lupus erythematosus and mixed connective tissue disease. Peripheral facial nerve palsy has been described to complicate the course of Sjögren's syndrome and sarcoidosis.
\end{abstract}

Keywords: Autoimmune disorders, hearing loss, sinusitis, voice hoarseness, oral ulcers.

Hospital do Servidor Público Estadual de São Paulo "Francisco Morato de Oliveira"- HSPE-SP. Recebido em 15/12/05. Aprovado, após revisão, em 31/01/06.

1. Médica residente do segundo ano do Serviço de Reumatologia do HSPE-SP.

2. Médico assistente responsável pela Enfermaria do Serviço de Reumatologia do HSPE-SP

3. Médica assistente responsável pelo Setor de Espondiloartropatias Soronegativas do Serviço de Reumatologia do HSPE-SP

4. Médico Diretor do Serviço de Reumatologia do HSPE-SP

Endereço para correspondência: Juliana Lasmar Ayres do Amaral, Rua Pedro de Toledo, n 1800, $9^{\circ}$ andar, Centro, São Paulo CEP 04029-000, SP, Brasil, telefone: (11) 5088-8099,Fax (11) 5084-6806, e-mail:wchahade@terra.com.br; cerir@cerir.org.br/; juliana.lasmar@ig.com.br 


\section{INTRODUÇÃO}

As manifestações otorrinolaringológicas nas doenças reumáticas representam um desafio diagnóstico para o reumatologista, o otorrinolaringologista e o médico generalista. Comumente, sintomas otorrinolaringológicos representam um sinal inicial de uma doença assintomática ou de uma desordem auto-imune não diagnosticada, que freqüentemente exige um imediato e agressivo tratamento imunossupressor. Neste texto foram revisadas as mais freqüentes manifestações otorrinolaringológicas das doenças do tecido conectivo, com ênfase em facilitar um diagnóstico e tratamento precoces ${ }^{(1)}$.

\section{DISTÚRBIOS DA AUDIÇÃO-AUDIOVESTIBULAR}

Os danos do ouvido têm sido ocasionalmente relatados como complicação no curso de várias doenças reumatológicas. Doença do ouvido interno imunomediada produz perda auditiva neurossensorial, enquanto outras manifestações como vertigens, tinido e uma ocasional sensação de plenitude auricular completam o expectro clínico da desordem ${ }^{(1)}$. Os pacientes podem apresentar uma diminuição da acuidade auditiva ou diminuição na discriminação do som. Doença do ouvido interno imunomediada tipicamente se desenvolve de forma subaguda ou em curso de tempo que varia desde poucos dias até vários meses. Costuma ter envolvimento bilateral (contudo os dois lados podem ser afetados de forma assimétrica ou ocasionalmente com um intervalo entre o envolvimento dos dois lados podendo chegar a um ano em raros casos) ${ }^{(1)}$. Um grupo de pacientes com doença limitada ao ouvido interno tem anticorpos séricos contra um antígeno do ouvido interno $(\mathrm{G} 8 \mathrm{KD})^{(1)}$. Perda auditiva neurossensorial, uni ou bilateral, predominantemente afetando média e alta freqüências, tem sido relatada em pacientes com lúpus eritematoso sistêmico (LES) e há evidência suficiente para suportar a forte associação entre a perda auditiva neurossensorial e a presença de altos títulos de anticorpos anticardiolipina. A perda auditiva neurossensorial subclínica tem sido descrita em mais de $22 \%$ dos pacientes com LES por alguns investigadores. Deficiência audiovestibular aguda também tem sido descrita na síndrome do anticorpo antifosfolípide primária $^{(2-5)}$. Existe uma evidência bibliográfica que sugere a forte associação entre perda auditiva neurossensorial e insuficiência aórtica aguda, uma rara manifestação do LES $^{(4)}$. Não há correlação entre o estado da doença ou a presença do fator antinúcleo (FAN) com o aparecimento da perda auditiva neurossensorial. A administração de antiinflamatórios não-hormonais e antimaláricos, prática clínica comum em pacientes com LES, tem sido associada à perda auditiva neurossensorial ${ }^{(2-5)}$. A perda auditiva neurossensorial de média e alta freqüências tem sido descrita em pacientes com esclerose sistêmica (ES). A perda auditiva mista tem sido descrita menos freqüentemente ${ }^{(6)}$. A perda auditiva neurossensorial no curso da síndrome de Sjögren (SS) é parcialmente atribuída à presença de altos títulos de anticorpos anticardiolipina ${ }^{(7)}$.

Vasculites associadas à mieloperoxidase (anticorpo anticitoplasma de neutrófilo perinuclear-p-ANCA) têm sido implicadas na patogênese da perda auditiva em pacientes com poliarterite nodosa e poliangeíte microscópica. Comumente, doença progressiva do ouvido, tanto neurossensorial como perda auditiva mista, representa a primeira manifestação da doença. Nestes casos, a presença de altos títulos de p-ANCA é extremamente útil no diagnóstico ${ }^{(8,9)}$.

Um déficit auditivo súbito ou gradual pode ocorrer em aproximadamente $50 \%$ de todos os pacientes com policondrite recidivante (PR) em algum momento da doença . O acometimento pode ocorrer em forma de perda auditiva condutiva (atribuída à expansão do processo inflamatório no ouvido médio e tuba auditiva), perda auditiva neurossensorial (vasculite da artéria auricular) ou déficit auditivo misto. Na PR o sintoma mais comum é a condrite auricular, que é caracterizada por início súbito de dor e edema, hiperemia e calor envolvendo a porção cartilaginosa do ouvido externo, poupando o lóbulo. PR grave com acometimento laringo-traqueal tem sido associada com perfuração auditiva. Ataques repetidos dão aparência mole e macia à orelha externa ${ }^{(10)}$.

O déficit otológico mais freqüente em pacientes com granulomatose de Wegener (GW) é a perda auditiva condutiva, resultado do envolvimento nasofaríngeo granulomatoso, disfunção secundária da tuba auditiva e otite média serosa. A otite média serosa resulta da inflamação e irritação pela secreção nasal no orifício da tuba auditiva. Manifesta-se por perda auditiva de condução sem dor ou sinais de inflamação aguda, contudo freqüentemente é complicada por episódios recorrentes de otite média aguda. Sinais clínicos incluem a presença de tímpano côncavo brilhante, com ou sem vasos superficiais e uma aparência amarelada. Alguns pacientes também sofrem de otite média purulenta, com dor, febre, sensação de pressão no ouvido, perda auditiva, tímpano saliente e hiperemiado (em fase aguda) ou perda auditiva sem dor e perfuração central da membrana timpânica nas formas crônicas. A perda audi 
tiva neurossensorial é menos freqüente e quando ocorre é tipicamente acompanhada de tinido sem vertigem. Padrões mistos são freqüentemente vistos e a ação tóxica dos produtos inflamatórios do ouvido médio, ou o envolvimento granulomatoso direto no ouvido interno, são considerados fatores predisponentes ${ }^{(1,11)}$.

A síndrome de Churg-Strauss e síndrome de Behçet raramente têm sido associadas com déficit audio-vestibu$\operatorname{lar}^{(12,13)}$.

A síndrome de Cogan é caracterizada por inflamação ocular (usualmente ceratite) e perda auditiva neurossensorial, que resulta de episódios recorrentes de doença do ouvido interno ${ }^{(14)}$. A detecção precoce da doença do ouvido interno imunomediada é de extrema importância para instituição de terapia agressiva com corticóide em tempo hábil, evitando perda auditiva irreversível ${ }^{(14)}$.

É de extrema importância a diferenciação de perda auditiva neurossensorial e condutiva para instituição do tratamento adequado (Tabela 1 ).

\section{TABELa 1}

DiAgNósticos DIFERENCIAIS DE PERDA AUDITIVA

\begin{tabular}{l|l}
\hline Neurossensorial & Condutiva \\
\hline Doença de Menière & Otite média aguda e crônica \\
\hline Barotrauma & Tumores de ouvido médio \\
\hline Exposição à ruído & Perfuração da membrana timpânica \\
\hline Presbiacusia & Lesões do ouvido externo \\
\hline Cocleíte viral & Osteomas \\
\hline $\begin{array}{l}\text { Agentes ototóxicos } \\
\text { (aminoglicosídeos e diuréticos) }\end{array}$ & $\begin{array}{l}\text { Carcinomas de células escamosas e } \\
\text { outros tumores }\end{array}$ \\
Meningite & Psoríase \\
\hline Isquemia cerebrovascular & Acúmulo de cerumen \\
\hline
\end{tabular}

Quando um tratamento agressivo é administrado a tempo, a função auditiva pode ser preservada ou recupe$\operatorname{rada}^{(1)}$. Um regime de três meses de prednisona que pode ser progressivamente reduzida até a retirada, usualmente controla a doença ${ }^{(1)}$. Se uma melhora significante não ocorrer até o fim da segunda semana ou se ocorrer uma recaída durante a diminuição do corticóide, ciclofosfamida deve ser adicionada ao tratamento com esteróide. Se a função auditiva não estiver sido restaurada até o fim da $12^{\underline{a}}$ semana, o dano auditivo é considerado irreversível e o tratamento é descontinuado ${ }^{(1)}$. O uso de metotrexato tem sido proposto como uma alternativa, no entanto, é menos efetivo e usado preferivelmente quando o diagnóstico da doença do ouvido interno imunomediada não tenha sido seguramente estabelecido e outros diagnósticos como a síndrome de Menière não tenha sido descartada. Contudo, um recente estudo randomizado incluindo 67 pacientes com perda auditiva neurossensorial bilateral rapidamente progressiva, mostrou que o metotrexato não foi benéfico na manutenção da melhora auditiva, alcançada através da terapia com prednisona ${ }^{(15)}$.

\section{NARIZ E SEIOS PARANASAIS}

A rinite alérgica está freqüentemente presente em pacientes com síndrome de Churg-Strauss. Sintomas típicos incluem prurido nasal, obstrução do fluxo aéreo, que são acompanhados de coriza e em casos mais severos por pressão facial, dor, edema periorbitário e cianose ${ }^{(16)}$. O exame nasal revela uma mucosa pálida e edemaciada, polipose nasal e subseqüente distúrbio do olfato pode complicar a doença. Sinusite recorrente é um achado comum, mas nem a rinite e nem a sinusite mostram o padrão destrutivo visto na GW e na $\mathrm{PR}^{(17)}$. Eosinofilia nasal junto com história positiva de asma, usualmente proeminente durante a fase inicial e presente em todos os pacientes com doença totalmente desenvolvida, apontam para o diagnóstico. Granuloma extravascular e lesão inflamatória rica em eosinófilos são os principais achados histopatológicos da mucosa nasal em Churg-Strauss. Eosinofilia periférica, infiltração eosinofilica de outros tecidos como o trato gastrintestinal e pulmões, e sintomas vasculíticos sistêmicos, infiltrados pulmonares, acometimentos cutâneo, cardíaco, do sistema nervoso e renal, são todas manifestações tardias da doença ${ }^{(17,18)}$. Anticorpo anticitoplasma de neutrófilo (ANCA) e hipergamaglobulinemia são úteis no diagnóstico para distinguir entre uma simples predisposição atópica e a presença de uma vasculite ativa ${ }^{(17,18)}$.

$\mathrm{Na}$ GW, obstrução nasal causada por crosta difusa, abundante secreção purulenta e descarga nasal sanguinolenta sugerem doença ativa. Necrose do septo cartilaginoso antecedida por destruição vascular da porção anterior do septo nasal pode levar à perfuração do septo, que junto com a deformidade nariz em sela causada por destruição maciça do tecido nasal, caracteriza mais tarde, contudo não necessariamente, doença ativa. Distúrbio do olfato pode ocorrer devido ao envolvimento extenso da mucosa, e infecção crônica por Staphylococcus aureus parcialmente responsiva a antibiótico é típico da $\mathrm{GW}^{(11)}$. 
O envolvimento do seio paranasal é de grande importância na GW. Durante a fase aguda - onde um curso bifásico de sintomas recorrentes de rinite, junto com febre alta, abundante secreção purulenta, cefaléia e seio paranasal sensível seguindo o início de uma rinite aguda - não se pode distinguir entre infecção e vasculite ativa. Secreção nasal posterior, tosse crônica, congestão nasal são todos sugestivos de sinusite crônica. Friabilidade da mucosa nasal junto com pólipo nasal ou nódulos difusos na submucosa são os mais freqüentes sinais clínicos. Recorrência ou piora dos sintomas usualmente leva o clínico à avaliação mais extensa. Pelo tempo, lesões granulomatosas ou espessamento difuso da mucosa junto com erosão ou destruição óssea do septo, erosão dos seios etimoidais e obliteração óssea completa dos seios maxilar, frontal e esfenoidal podem ser observados pela tomografia computadorizada ${ }^{(19)}$. A mastóide também é comumente envolvida. Granulomas podem ser detectados como lesões de baixo sinal em T1 e T2 em ressonância nuclear magnética (RNM) da cavidade nasal ou seios paranasais. O envolvimento intraorbitário da GW é usualmente acompanhado de doença do seio paranasal e um hiposinal em T2 na RNM é útil no diagnóstico ${ }^{(20,21)}$. Obstrução do ducto nasolacrimal e um aumento das glândulas lacrimais também pode ocorrer. A histologia revela uma vasculite granulomatosa necrotizante com variados graus de inflamação crônica ${ }^{(22)}$.

Anormalidades das vias aéreas superiores estão freqüentemente presentes à apresentação, com 92 a 99\% dos pacientes desenvolvendo os sintomas durante todo o curso da doença ${ }^{(23)}$. Comumente, pacientes não apresentam envolvimento renal ou pulmonar no estágio inicial, apesar de 70 a $80 \%$ deles finalmente se apresentar com doença pulmonar e/ou renal ${ }^{(23)}$. Nódulos e infiltrados pulmonares podem ser assintomáticos e a doença renal pode progredir para uremia sem manifestações clínicas evidentes ${ }^{(23)}$.

O c-ANCA pode ser negativo em uma significante porcentagem dos casos, particularmente na ausência de doença severa ${ }^{(23)}$. Quando episódios de sinusite persistentes, recorrentes ou atípicos ocorrem, uma avaliação mais extensa incluindo raio $\mathrm{X}$ de tórax, medida da creatinina sérica, ANCA, urinálise e, finalmente, a biópsia do sítio envolvido deve ser considerada ${ }^{(23)}$.

Quadro de GW localizada sem envolvimento pulmonar ou renal, mas ANCA positivo e com histologia compatível tem sido reconhecido como um subtipo distinto da doen$c^{a^{(24)}}$. Além disso realça a predileção da GW pela região da cabeça e pescoço, denotando as manifestações freqüentes de cada paciente quanto ao aspecto otorrinolaringológico e o papel crucial da alta suspeita clínica e confirmação sorológica para diagnóstico e tratamento precoces ${ }^{(24)}$.

Obstrução nasal e rinorréia, crostas e epistaxe podem também ser vistas em paciente com PR. Mais tarde, quando a inflamação sustentada ou recorrente da cartilagem se desenvolve, perfuração do septo e/ou deformidade nariz em sela pode ocorrer. Como na GW, o olfato também pode ser comprometido. Condrite nasal está presente em 29\% dos pacientes com PR no início da doença, enquanto 53\% desenvolverá eventualmente a lesão ${ }^{(25)}$. Condrite articular, não erosiva, assimétrica, poliartrite migratória, inflamação ocular, condrite do trato respiratório com rouquidão e infecções subseqüentes, disfunção coclear ou vestibular e manifestações cardíacas freqüentemente coexistem. Observa-se que o envolvimento das vias aéreas superiores e inferiores é, algumas vezes, assintomático e o não reconhecimento até que o aparecimento de infecção secundária recorrente tenha ocorrido ${ }^{(25)}$.

Obstrução nasal, rinorréia, crosta, necrose de seio e destruição do palato têm sido relatados em pacientes com sarcoidose, geralmente, antecedendo as outras manifestações como linfadenopatia hilar bilateral, envolvimento pulmonar, hepático, da pele e sistema nervoso central ${ }^{(26)}$. Perfuração do septo nasal manifestando-se com obstrução, epistaxe, descarga nasal posterior e crosta pode ser vista em pacientes com LES ou síndrome do anticorpo antifosfolípide secundária e é atribuída à isquemia ou inflamação local ${ }^{(27)}$.

Infecções granulomatosas e não-granulomatosas como tuberculose e rinosinusite fúngica respectivamente, e linfoma de células $\mathrm{T}$, hanseníase, carcinoma e sarcoma, devem ser incluídos no diagnóstico diferencial de doença crônica do seio paranasal.

\section{INJÚRIAS ORAL, FARÍNGEA E LARÍNGEA}

No LES, usualmente, mas não invariavelmente, úlceras orais pouco dolorosas, caracteristicamente localizadas no palato mole e duro, que ocasionalmente desenvolvem uma depressão central e até perfuração, representam achado clínico comum ${ }^{(27)}$.

Ulceração oral dolorosa recorrente representa uma importante manifestação precoce da doença de Behçet. Tipicamente extensas e múltiplas e envolvidas por eritema. Elas aparecem geralmente antes de outras manifestações da doença (ulceração genital, uveíte, lesões cutâneas, artrite, envolvimento de grande vaso como trombose venosa profunda e aneurisma arterial) ${ }^{(28)}$.

Úlcera mucosa dolorosa e profunda em língua, bochecha, palato e gengiva associado à "hiperplasia gengival 
em morango", tem sido descrita em raros casos de GW complicada. PR, artrite reativa e doença mista do tecido conjuntivo também podem se manifestar com ulcerações orais ${ }^{(25)}$. Corticosteróides tópicos e sistêmicos, colchicina e agentes biológicos como o etanercepte têm sido propostos no controle de úlceras aftosas recorrentes severas ${ }^{(29)}$.

Xerostomia é uma invariável característica da síndrome de Sjögren, sendo comum em pacientes com a síndrome primária e secundária. Cáries dentárias e candidíase oral são complicações sérias, ocorrendo em aproximadamente 65 e $50 \%$ dos pacientes, respectivamente ${ }^{(30)}$.

O aumento da glândula salivar é outra manifestação comum da síndrome de Sjögren. As glândulas parótidas e/ ou submandibulares são unilateralmente ou com mais freqüência bilateralmente afetadas. As glândulas são firmes, não-sensíveis e difusamente aumentadas no exame físico (sialodenite linfoepitelial) ${ }^{(31)}$. Pacientes com síndrome de Sjögren têm um maior risco de desenvolver um linfoma de glândula salivar ou extrasalivar e mais freqüentemente linfoma MALT (mucosal-associated lymphoid tissue). Um persistente aumento das glândulas parótidas, baixo nível de C4 e púrpura palpável sugerem uma potencial evolução para linfoma e tem que ser considerada durante a avaliação do aumento da glândula parótida ${ }^{(30)}$. Em análise de um aumento unilateral da glândula salivar, uma neoplasia como adenoma pleomórfico, adenocarcinoma ou outro tumor primário de glândula salivar também devem ser descartados. Outras potenciais causas de aumento bilateral de glândula salivar incluem infecções virais, amiloidose, cisto linfoepitelial (HIV+ ou não), tuberculose, hanseníase, alcoolismo ou cirrose, hiperlipidemia, e coexistência de outros parâmetros clínicos devem ser consideradas antes de atribuir o aumento da glândula salivar à síndrome de Sjögren.

A síndrome de Heerfordt é definida como uma combinação de aumento bilateral das parótidas, uveíte anterior, febre e paralisia facial, e é encontrada em pacientes com sarcoidose. Contudo, dor isolada e aumento unilateral da glândula salivar também têm sido descritos como achados clínicos comuns nesses pacientes ${ }^{(26)}$.

Inflamação orofaríngea e episódios recorrentes de faringite resistente à terapêutica têm sido relatados como uma importante manifestação clínica precoce da doença de Still do adulto. Em um grande estudo, inflamação orofaríngea estava presente em aproximadamente $92 \%$ dos pacientes que preencheram critério diagnóstico para doença de Still do adulto ${ }^{(32)}$. Em uma revisão de 369 casos de doença de Still do adulto na literatura inglesa, $69 \%$ dos pacientes se apresentaram com inflamação orofaríngea persistente como manifestação clínica inicial ${ }^{(32)}$. Artralgia ou artrite, erupção cor salmão, febre alta e linfadenopatia palpável podem ou não coexistir nesses estágios precoces.

A mucosa seca persistente e secreção defeituosa da inflamação subaguda que afeta a faringe, traquéia e brônquio, produzem uma tosse seca irritativa em pacientes com síndrome de Sjögren. Doença do refluxo gastroesofágico, asma, gotejamento nasal posterior crônico, bronquite crônica, bronquiectasia e administração de inibidores da enzima conversora de angiotensina (IECA) têm sido considerados na avaliação de tosse crônica ${ }^{(31)}$.

A articulação cricoaritenóide pode ser potencialmente afetada durante o curso de várias artropatias inflamatórias. A artrite reumatóide (AR) é complicada por artrite cricoaritenóide em 30\% dos casos. Inflamação orofaríngea, rouquidão e estridor inspiratório são as manifestações clinicas mais comuns. Obstrução das vias aéreas requerendo traqueostomia imediata tem sido descrita. A laringoscopia revela hiperemia e edema, redução da motilidade da corda vocal, fechamento incompleto da comissura posterior (que favorece aspiração) e cartilagem aritenóide assimétrica. Ocasionalmente um significante estreitamento da fissura glótica pode ser notado. Erosão e luxação da articulação cricoaritenóide e um tecido edemaciado ao redor, pode ser demonstrado em tomografia de alta resolução ${ }^{(33)}$.

Obstrução das vias aéreas superiores devido ao envolvimento laríngeo é raro, mas é complicação bem documentada do LES, que usualmente ocorre em associação com outros sinais e sintomas que indicam doença ativa. Imobilidade bilateral da corda vocal pode ocorrer. Interessante observar que a artrite cricoaritenóide do LES é altamente responsiva a tratamento com esteróide, que é usualmente inadequado na artrite cricoaritenóide da $\mathrm{AR}^{(33,34)}$.

$\mathrm{Na}$ PR, o envolvimento laringotraqueal deverá ser acompanhado de laringoscopia e tomografia computadorizada seriados. A traqueostomia é necessária para tratar os sintomas de estenose subglótica. Nos casos de envolvimento difuso da via aérea, causando colapso por flacidez, não há terapia efetiva, e o uso de stent traqueal é de resultado limitado. A reconstrução cirúrgica do septo nasal colapsado não é recomendado, visto que freqüentemente ocorre recidiva após a cirurgia ${ }^{(10)}$.

Espondilite anquilosante também pode afetar a articulação cricoaritenóide. Fixação da corda vocal unilateral e mais raramente bilateral com manutenção da posição em adução da corda parece ser manifestação tardia da doença descontrolada ${ }^{(35)}$.

Artrite gotosa laríngea com rouquidão, disfonia e 
disfagia pode acompanhar o envolvimento de múltiplas articulações ou aparecer como uma manifestação isolada da gota. Tofo em laringe ou corda vocal causando sintomas similares raramente tem sido descrito ${ }^{(36)}$.

Ulceração degenerativa na articulação cricoaritenóide lembrando osteoartrite (OA) também pode ocorrer. Esta alteração estrutural é comparada com a $\mathrm{OA}$ de membros e pode levar à movimentação prejudicada da cartilagem aritenóide (prejudicar a qualidade da voz e reduzir a atividade vocal). Em um estudo, $50 \%$ das articulações laríngeas em pacientes com mais de 40 anos de idade exibiram alterações degenerativas ${ }^{(37)}$.

Laringite aguda, doença do refluxo gastroesofágico, gotejamento nasal posterior crônico, tabagismo, álcool e esforço vocal crônico (potencial causa de laringite crônica), disfonia espasmódica, hipotireoidismo, pólipos e nódulos em corda vocal, paralisia laríngea (pós-tireoidectomia ou devido à outras causas), desordens da laringe e câncer laríngeo representam alguns dos fatores etiológicos de rouquidão e disfonia, que devem ser excluídos. Estenose subglótica grave causando dispnéia intensa aguda e requerendo traqueostomia tem sido descrita em pacientes com GW. Este grupo de pacientes com estenose subglótica grave, independente da atividade da doença e tipo de terapia, costuma não responder ao tratamento sistêmico imunossupressor ${ }^{(38)}$.

Em paciente com dermatomiosite ou polimiosite, acalasia cricofaríngea devido à atividade prejudicada do músculo cricofaríngeo, pode causar disfagia orofaríngea, manifestando-se com dificuldade para engolir líquidos, disartria e disfonia. O músculo cricoaritenóide posterior é o único músculo capaz de manter as cordas vocais em adução e quando ele é comprometido as cordas vocais se juntam e pode ocorrer obstrução das vias aéreas. Disfagia orofaríngea pode favorecer complicação por aspiração do conteúdo esofágico para dentro das vias aéreas ${ }^{(39)}$.

Estreitamento da abertura oral, rigidez do palato mole, laringe e mucosa oral, são responsáveis por disfagia orofaríngea na esclerose eistêmica ${ }^{(40)}$. Videoesofagoscopia é a ferramenta diagnóstica útil para avaliação da disfagia orofaríngea.

Síndrome de Sjögren primária tem sido descrita afetando a contratilidade do terço superior do esôfago (evidenciado por estudos manométricos), induzindo sintomas de refluxo esofagolaríngeo e disfagia ${ }^{(41)}$.

A síndrome da articulação têmporo-mandibular (ATM) manifesta-se com dor, que é usualmente localizada ao redor da orelha ou região pré-auricular, pode irradiar-se pela orelha, mandíbula, dentes ou região cervical e é exacerbada pela mastigação. Cefaléia e raramente tinido são sintomas típicos; crepitação durante manobras articulares, motilidade restrita da mandíbula e edema doloroso articular podem ser evidenciados no exame físico. Contudo, o desarranjo interno devido à carga micro ou macrotraumática representa a mais freqüente causa da síndrome da ATM e o clínico deve ter em mente que a ATM pode ser afetada durante o curso das artropatias inflamatórias, como AR, síndrome de Sjögren, espondiloartropatias soronegativas e $\mathrm{OA}^{(42)}$. Bruxismo noturno psicogênico ou má oclusão da mandíbula, anormalidades dentárias ou manipulações, anormalidade anatômica da ATM e eventualmente desordens linfoproliferativas, neuralgia trigeminal ou glossofaríngea e desordens da glândula parótida, devem ser consideradas durante a avaliação da sintomatologia da $\mathrm{ATM}^{(42)}$.

A mastigação ou fala prolongadas levam à claudicação da mandíbula em pacientes com arterite de células gigantes. Dor no couro cabeludo, cefaléia, amaurose fugaz ou neuropatia óptica isquêmica e sintomas de polimialgia reumática como rigidez e dor em ombros e cintura pélvica, representam manifestações comuns associadas. Claudicação da mandíbula também tem sido descrita em pacientes com poliarterite nodosa, síndrome de Churg-Strauss e amiloidose primária, e a avaliação clínica junto com a análise histológica da artéria temporal são necessárias para confirmar o diagnóstico ${ }^{(43,44)}$.

\section{DOENÇA FACIAL}

Neuropatia trigeminal que poupa a divisão oftálmica do nervo (preservando o reflexo corneano) e presente com perda sensitiva bilateral em face ou fraqueza da musculatura mandibular tem sido descrita em pacientes com síndrome de Sjögren ${ }^{(45)}$. A neuropatia trigeminal também tem sido demonstrada em pacientes com esclerose sistêmica e doença mista do tecido conjuntivo ${ }^{(46,47)}$.

A paralisia do nervo facial tem sido mostrada como complicação no curso de várias doenças do tecido conjuntivo. Síndrome de Sjögren e sarcoidose são as doenças reumatológicas mais comumente associadas com a paralisia do nervo facial. Em pacientes com sarcoidose a paralisia facial periférica pode ser uni ou bilateral (simultanea ou seqüencialmente) e recorrente. Algumas outras causas de paralisia facial aguda incluem a paralisia de Bell (possivelmente devido ao vírus herpes simples), infecção por varicela zoster (síndrome de Ramsay-Hunt), síndrome de Guillain-Barré, doença de Lyme, otite média aguda ou crônica e colesteatoma em ouvido médio. Cautela deve ser tomada na avaliação de 
paralisia facial permanente ou recorrente, visando a presença de neoplasias como a malignidade da parótida e do osso temporal, paragangliomas do ouvido médio, colesteatomas ou outras lesões neoplásicas afetando o nervo facial ${ }^{(45,48)}$.

\section{REFERÊNCIAS}

1. Stone JH, Francis HW: Immune mediated inner ear disease. Curr Opin Rheumatol 12:32-40, 2000.

2. Kastanioudakis I, Ziavra N, Voulgari PV, Exarchakos G, Skevas A, Drosos AA: Ear involvement in systemic lupus erytematosus patients: a comparative study. J Laryngol Otol 116: 103-7, 2002.

3. KobayashiI S, Fujisimoto N, Sugiyava K: Systemic lupus erythematosus with sensorineural hearing loss and improvement after plasmapheresis using the double filtration method. Intern med 31: 778-81, 1992.

4. Peeva E, Barland P: Sensorineural hearing loss in conjunction with aortic insufficiency in systemic lupus erythematosus. Scand J Rheumatol 30: 45-7, 2001.

5. Vyse T, Luxon LM, Walport MJ: Audiovestibular manifestations of the antiphospholipid syndrome. J Laryngol Otol 108: 57-9, 1994.

6. Kastanioudakis I, Ziavra N, Politi EN, Exarchakos G, Drosos AA, Skevas A: Hearing loss in progressive systemic sclerosis patientes. A comparative study. Otolaringol head Neck Surg 124: 522-5, 2001.

7. Tumiati B, Casoli P, Parmegiani A: Hearing loss in Sjogren's syndrome. Ann Intern Med 126: 450, 1997.

8. Tsunoda K, Akaogi J, Ohya N, Murofushi T: Sensorineural hearing loss as the initial manifestation of polyarteritis nodosa. J Laryngol Otol 115: 311-2, 2001.

9. Koseki Y, Suwa A, Najima T et al: A case of microspic polyangiitis accompanied by hearing loss as the initial sign of disease. Ryumachi 37: 804, 1997.

10. Cody DTR, Sones DA: Relapsing polychondritis: Audiovestibular manifestations. Laryngol 81: 208-22, 1971.

11. Rausmussen N: Management of the ear, nose and throat manifestations of Wegener's granulomatosis: an otorhinolaryngologist's perspective. Curr Opin Rheumatol 13: 3-11, 2001.

12. Sale S, Patterson R: Recurrent Churg Strauss vasculitis with exopthalmos, hearing loss, nasal obstruction, amyloid deposits, hyperimmunoglobulinemia $\mathrm{E}$ and circulating immune complexes. Arch Intern Med 141: 1363-5, 1981.

13. Adler YD, Jovanovic S, Jivanjee A, Krause L, Zouboulis CC: Adamantades-Behçet's disease with inner ear involvement. Clin Exp Rheumatol 20 (Suppl. 36): S40-S42, 2002.

14. Edrees A, Tran J, Thomson G, Watson KR, Godfrey W, Abdou NI: Cogan's syndrome presenting as Sjögren's syndrome folowed by acute aortic regugitation. Clin Rheumatol 22: 156, 2003.

15. Harris JP, Weisman MH, Derebery JM, et al: Treatment of corticosteroid-responsive autoimmune inner ear disease with methotrexate: a randomized controlled trial. JAMA 290: 1875$83,2003$.
16. Naclerio RM: Allergic rhinitis. N Engl J Med 325: 860-9, 1991.

17. Guillevin L, Cohen P, Gayraud M, et al: Churg-Strauss syndrome Clinical study and long term follow up of 96 patients. Medicine (Baltimore) 78: 26-37, 1999.

18. Hoffman GS: Vasculitides. In KLIPPEL J (Ed.): Primer on the Rheumatic Diseases. 12th ed. 392-6, 2002.

19. Yang C, Talbot JM, Hwang PH: Bony abnormalities of the paranasal sinuses in patients with Wegener's granulomatosis. Am j Rhinol 15: 121-5, 2001.

20. Muhle C, Reinnhold-keller E, Richter C et al: MRI of the nasal cavity, the paranasal sinuses and orbits in Wegener's granulomatosis. Eur Radiol 7: 566-70, 1997.

21. Provenzale JM, Allen NB: Wegener's granulomatosis. CT and MRI findings. AJNR Am J Neurocardiol 4: 785-92, 1996.

22. Boutes RJ, DE Vries-Knoppert WA: Lacrimal gland enlargement as one of the ocular manifestations of Wegener granulomatosis. Doc Opthalmol 59: 21-6, 1985.

23. Hoffman GS: Vasculitides. Wegener granulomatosis and Churg Strauss vasculitis. In KLIPPEL J (Ed.): Primer on the Rheumatic Diseases. 12th ed. 392-6, 2002.

24. Ahmad I, Lee WC, Nagendran V, Wilson F, Shortridge RT.: Localised Wegener's granulomatosis in otolaryngology: a review of six cases. ORL J Otorhinolaryngology Relat Spec 62: 149-55, 2000.

25. Harisdangkul V: Relapsing polychondritis. In Klippel j (Ed): Primer on the Rheumatic Diseases. 12 ${ }^{\text {th }}$ ed. 419-22, 2002.

26. Milton CM: Sarcoidosis in ENT practice. Clin Otolaryngol 10:351-5, 1985.

27. Buyon JP: Systemic lupus erythematosus. Clinical and laboratory features. In KLIPPEL J (Ed): Primer on the Rheumatic Diseases. $12^{\text {th }}$ ed. 335-46, 2002.

28. Sakane T, Takenko M, Suzuki N, Inaba G: Behçet's disease. N Engl J Med 341: 1284-91, 1999.

29. Scheinberg MA: Treatment of recurrent oral aphthous ulcers with etanercept. Clin Exp Rheumatol 20: 733-4, 2002.

30. Bell M, Askari A, Bookman A et al: Sjogren's syndrome: a critical review of clinical management. J Rheumatol 26: 2051$61,1999$.

31. Moutsopoulos HM: Disorders of the immune system, connective tissue and joints. In Harrison's Principles of Internal Medicine, 14th ed. Table 316.4. Section 2. Disorders of immune- mediated injury. 316. Sjögren's syndrome.

32. Pouchot J, Esdaile JM, Baudet E et al: Adult Still's disease: manifestations disease course and outcme in 62 patients. Medicine (Baltimore) 70: 118-36, 1991.

33. Kolman J, Morris I: Cricoarytenoid arthritis. A cause of acute upper airway obstruction in rheumatoid arthritis. Can J Anaesth 49: 729-32, 2002.

34. Karim A, Ahmed S, Siddiqui R, Marder GS, Mattana J: Severe upper airway obstruction from cricoarytenoiditis as the sole 
presenting manifestation of a systemic lupus erythematosus flare. Chest 121: 990-3, 2002.

35. Miller FR, Wanamaker JR, Hicks DM, Tucker AM: Cricoarytenoid arthritis and ankylosing spondylitis. Arch Otolaryngol Head Neck Surg 120: 214-6, 1994.

36. Guttenplan MD, Hendrix RA, Townsend MJ, Balsara G: Laryngeal manifestations of gout. Ann Otol Rhinol Laryngol 100: 899-902, 1991.

37. Paulsen FP, Tillmann BN: Osteoarthritis in the cricoarytenoid joint. Osteoarthritis Cartilage 7:505-14, 1999.

38. Langford CA, Sneller MC et al: Clinical features and therapeutic management of subglottic stenosis in patients with Wegener`s granulomatosis. Arthritis Rheum 39: 1754-60, 1996.

39. Kagen LI, Hochman RB, Strong EW: Cricopharyngeal obstruction in inflammatory myopathy ( polymyositis/dermatomyositis). Report of three cases and review of the literature. Arthritis Rheum 28: 630-6, 1985.

40. Montesi A, Pesaresi A, Cavalli ML et al: Oral pharyngeal and esophageal dysfunction in scleroderma. Dysphagia 6: 219-23, 1991.

41. Ramirez-Mata M, Pena-Ancira FF, Alarcon-Segovia D: Abnormal esophageal motility in primary Sjogren's syndrome. J Rheumatol 3: 63-9, 1976.
42. Gynther GW, Holmlund AB, Reinholt FP, Lindblad S: Temporomandibular joint involvement in generalized osteoarthritis and rheumatoid arthritis: a clinical, arthroscopic, histologic, and immunohistochemical study. Int J Oral Maxifollac Surg 26: 10-6, 1997.

43. Kruithof E, Elewaut D, Naeyaert JM et al: Polyarteritis nodosa mimicking polymyalgia rheumatica. Clin Rheumatol 18: 257-60, 1999.

44. Churchill CH, Abril A, Krishna M, Callman ML, Ginsburg WW: Jaw claudication in primary amyloidosis: usual presentation of a rare disease. J Rheumatol 30: 2283-6, 2003.

45. Mellgren SI, Conn DL, Stevens JC et al: Peripheral neuropathy in primary Sjogren's syndrome. Neurology 39: 390-4, 1989.

46. Alfaro-Giner A, Penarrocha-Diago M, Bagan-Sebastian JV.: Orofacial manifestations of mixed connective tissue disease with an uncommon serologic evolution. Oral Surg Oral Med Oral Phatol 73: 441-4, 1992.

47. Wigley FM: Systemic scleroris: Clinical features. In KLIPPEL J (Ed.): Primer on the Rheumatic Diseases. 12 ${ }^{\text {th }}$ ed. 357-64, 2002. 48 - Stern BJ, Krumholz A, Johns C, Scott P, Nissim J: Sarcoidosis and its neurological manifestations. Arch Neurol 42: 909-17, 1985. 